\title{
Adaptive optics requirements definition for TMT
}

Richard G. Dekany, Matthew C. Britton, Don T. Gavel, Brent L. Ellerbroek, Glen Herriot, et al.

Richard G. Dekany, Matthew C. Britton, Don T. Gavel, Brent L. Ellerbroek, Glen Herriot, Claire E. Max, Jean-Pierre Veran, "Adaptive optics requirements definition for TMT," Proc. SPIE 5490, Advancements in Adaptive Optics, (25 October 2004); doi: 10.1117/12.552911

Event: SPIE Astronomical Telescopes + Instrumentation, 2004, Glasgow, United Kingdom 


\title{
Adaptive Optics Requirements Definition for TMT
}

\author{
Richard Dekany ${ }^{1}$, Matthew Britton ${ }^{1}$, Don Gavel$^{2}$, Brent Ellerbroek ${ }^{3}$, \\ Glen Herriot ${ }^{4}$, Clare $\mathrm{Max}^{2}$, Jean-Pierre Veran ${ }^{4}$ \\ ${ }^{1}$ Caltech Optical Observatories, California Institute of Technology \\ Pasadena, CA 91125 \\ ${ }^{2}$ University of California, Santa Cruz \\ Santa Cruz, CA 95064 \\ ${ }^{3}$ New Initiatives Office, National Optical Astronomical Observatories \\ Tucson, AZ 85719 \\ ${ }^{4}$ Hertzberg Institute of Astrophysics, Dominion Astronomical Observatory \\ Victoria, BC V9E 2E7
}

\begin{abstract}
The scientific return on adaptive optics on large telescopes has generated a new vocabulary of different adaptive optics (AO) modalities. Multiobject AO (MOAO), multiconjugate AO (MCAO), ground-layer AO (GLAO), and extreme contrast $\mathrm{AO}$ (ExAO) each require complex new extensions in functional requirements beyond the experience gained with systems operational on large telescopes today. Because of this potential for increased complexity, a more formal requirements development process is recommended. We describe a methodology for requirements definition under consideration and summarize the current scientific prioritization of TMT AO capabilities.
\end{abstract}

Keywords: Extremely large telescopes, multiconjugate adaptive optics, extreme adaptive optics, ground-layer adaptive optics, tomographic wavefront sensing

\section{INTRODUCTION}

Following a multi-year feasibility study phase ${ }^{1,2,3,4,5}$, TMT is poised to begin formal development of observatory and subsystem level requirements. The TMT adaptive optics subsystem functional requirement are proposed to be developed using an industry standard process ${ }^{6,7}$ depicted in the functional cascade shown in the left-hand side of Figure 1. The right-hand side of Figure 1 maps onto this process the design documentation associated with this process, as applied to large telescopes in general and TMT in particular.

During the past two years, significant and frequent interaction between the TMT astronomer and engineer community has taken place. The results of these discussions will be a Science Requirement Document (SRD) to be placed under formal change control. The SRD defines the needs of the end users, the scientific goals, and the objectives, or explicit initiatives, that will satisfy the project goals. With this scope definition in hand, the major drivers that will shape the implementation of the initiatives can be identified. In order to determine these drivers, a number of tools must be developed, validated, and exercised, including development of error budgets, conceptual designs, parametric models, and detailed subsystem simulations ${ }^{8}$. Having identified the major design drivers, operational scenarios must be developed to understand the operational requirements upon the observatory. These scenarios, if properly formulated to include routine observing, observing exceptions, maintenance, and emergency situations help to define the major interfaces and interactions between various observatory subsystems. Having developed and documented these, we must then consider the system risks, most of which arise from lack of sufficient information. Technical challenges, unclear subsystem boundaries, uncertain technical resources, and evolution of user needs must be 
considered. Only after all these steps are taken, can we formally develop Functional Requirements Documents (FRDs) for each of the observatory subsystems, including the AO capabilities.

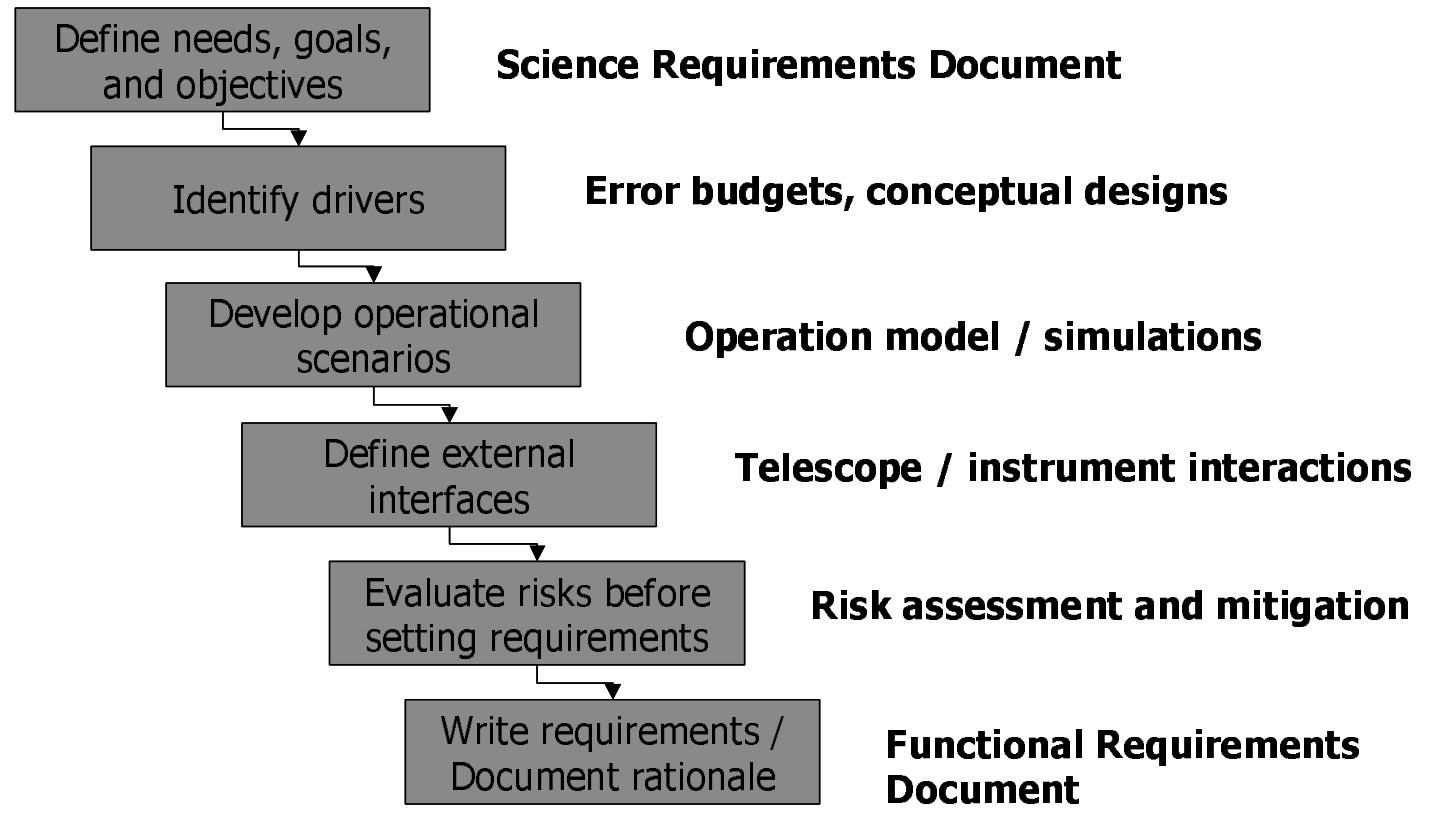

Figure 1. Proposed AO functional requirements development process.

\section{TMT SCIENTIFIC PRIORITIES}

Although the TMT SRD has not yet been placed under formal revision control, it is still instructive to consider the science capability prioritization captured in a recent SRD draft ${ }^{9}$. We summarize one possible scientific capability prioritization desired by our science community in Table 1, capability \#1 being the most highly desired. For each item, we list whether or not the mode requires AO, the desired spatial field of view (FoR) or field of regard (FoR), for the cases of deployable or sparsely sampled fields, whether the capability is primarily a spectroscopic or imaging mode, the approximate spatial sampling, the desired spectral resolution, and the scientific wavelength coverage.

In the case of the wide-field optical spectrograph (capability \#2), we are continuing to evaluate the costeffectiveness of ground-layer adaptive optics (GLAO) as specifically implemented with several alternative implementation concepts. Although GLAO performance is believed to degrade with decreasing observing wavelength ${ }^{10}$, it remains a compelling option in terms of improving residual telescope errors, dome seeing, and very low-altitude boundary layer seeing.

\section{TMT AO OBSERVING MODES}

The mapping of these scientific capabilities onto a set of adaptive optics capabilities, which has evolved somewhat in the past two years ${ }^{1}$, is presented in Table 2 . In addition, we associate here with each AO mode the enable science, as drawn from the SRD, the potential science instrument feed, and the relative priority of implementation, as envisioned today. Multi-object AO (MOAO) is an intriguing, but yet unproven, capability that offers several potential benefits over Multiconjugate $\mathrm{AO}\left(\mathrm{MCAO}^{11}\right)$. 


\begin{tabular}{llllll} 
& & Field Mode & Spatial & Spectral & Wavelength $(\mu \mathrm{m})$ \\
\hline 1. & AO $10 "$ FoV n-IFU & $\lambda / \mathrm{D}$ & $\mathrm{R} \sim 4,000$ & $0.6-5$ \\
2. & (---) 20 ' FoR N-Slit & $\mathrm{r}_{0} / \mathrm{D}(/ 2)$ & $150<\mathrm{R}<6,000$ & $0.3-1.3$ \\
3. & AO 10" FoV 1-Slit & $\lambda / \mathrm{D}$ & $5,000<\mathrm{R}<100,000$ & $5-28$ \\
4. & AO 5' FoR n-IFU & $\sim \lambda / \mathrm{D}$ & $2,000<\mathrm{R}<10,000$ & $0.8-2.5$ \\
5. & AO 2" FoV $~ 10^{8}$ contrast & $\lambda / \mathrm{D}$ & $50<\mathrm{R}<300$ & $1-5$ \\
6. & AO 2" FoV 1-Slit & $\lambda / \mathrm{D}$ & $20,000<\mathrm{R}<100,000$ & $1-5$ \\
7. ---- 5" FoV 1-Slit & $\mathrm{r}_{0} / \mathrm{D}$ & $50,000<\mathrm{R}<100,000$ & $0.3-1.3$ \\
8. & AO 30" FoV Imaging & $\lambda / \mathrm{D}$ & $5<\mathrm{R}<100$ & $0.6-5$
\end{tabular}

- Notes:

- FoV $=$ Field of View, FoR $=$ Field of Regard (fields quoted by diameter)

$-\mathrm{N}>\mathrm{n}>>1$

- (/2) Indicates GLAO option - to be evaluated

Table 1. Example scientific prioritization from working draft of the Science Requirements Document. Note the pervasiveness of adaptive optics. Here, $\mathrm{N}$ or $\mathrm{n}$ represent the (undefined) multiplexing of the capability, and IFU suggests an integral field unit spectroscopic capability.

MOAO is envisioned using a 'one AO system per object' implementation, wherein each field object is separately corrected by an independent wavefront corrector. Control signals are provided to each deformable mirror $(\mathrm{DM})$, based upon a tomographic reconstruction of the atmosphere using multiple laser beacons. These $\mathrm{n}$ separate correctors might or might not share a global woofer mirror, such as an adaptive telescope secondary. The advantages of MOAO include a reduction in the number of science reflections (which increases throughput and can reduce emissivity), more compact packaging (due to the relatively small field of view (FoV) seen by each DM), and better potential performance (as each DM can be tuned to optimize the wavefront correction in each particular direction in the sky). On the other hand, MOAO as currently envisioned requires that each DM operate in open-loop, namely that the corrections applied to each science field are at no time directly measured by the wavefront sensors. Instead, the wavefront sensors operate in a non-null-seeking mode which relies on exquisite calibration of the wavefront sensor and deformable mirrors. Thus, MOAO requires sensors and actuators of unusually high linearity and dynamic range. The experimental validation of the MOAO concept, at the required level of accuracy, is a near-term necessity before TMT endorses such an implementation in its baseline.

The technical challenges associated with each of the AO capabilities currently under consideration are presented in Table 3, along with our best estimates of the state-of-the-art within each technical area today. We also note the potential risk mitigations strategies to bridge the technical gap and possible fallback positions, either alternative technology levels or system impacts, in the event that unforeseen issues deter us from executing our research and development program completely through to our current performance specifications. In many areas, the lack of components of sufficiently mature technology is a major driver for the development of AO functional requirements.

\section{RISK ASSESSMENT}

Prior to the establishment of $\mathrm{AO}$ system functional requirements, it is essential to consider the range of potential risks among plausible conceptual implementations. While this is often done informally based upon engineering judgment, the potential complexity and conceptual diversity of TMT AO systems motivates us to take a more formal approach. As benefits, formal quantitative risk assessment: 


\begin{tabular}{|c|c|c|c|c|}
\hline $\begin{array}{l}\text { AO Mode } \\
\text { (w/ corresponding } \\
\text { science capability ) }\end{array}$ & $\begin{array}{l}\text { Wavelength } \\
\text { range }\end{array}$ & Enabled science & $\begin{array}{l}\text { Components/ } \\
\text { Instrument feed }\end{array}$ & Priority \\
\hline $\begin{array}{l}\text { MOAO } \\
\text { a.Small-Field (\#1, \#6) } \\
\text { b.Multi-Objects on } \\
\text { wide-field (\#4) }\end{array}$ & $\begin{array}{l}\text { a) } 0.65-5 \mu \\
\text { b) } 1-2.5 \mu\end{array}$ & $\begin{array}{l}\text {-Galaxy chemistry } \\
\text {-Star forming chemistry }\end{array}$ & $\begin{array}{l}\text {-Multi Lasers } \\
\text {-Deployable AO } \\
\text {-MEMS } \\
\text {-a) } 0.005 \text { " IFU } \\
\text { •b) } 0.025-0.040 \text { " IFU }\end{array}$ & $\begin{array}{l}1^{\text {st }} \text { light, if } \\
\text { successfully } \\
\text { demonstrated }\end{array}$ \\
\hline $\begin{array}{l}\text { MIRAO } \\
\text { Mid IR (\#3) }\end{array}$ & $7-28 \mu$ & $\begin{array}{l}\text {-Star forming regions, protoplanetary disks } \\
\text {-Characterize planetary systems; AGNs }\end{array}$ & $\begin{array}{l}\text {-Cryogenic DM or } \\
\text {-Adaptive Secondary } \\
\text {-NGS or multi-lasers } \\
\text {-MidIR Echelle Spectrometer } \\
\text {-MidIR Imager }\end{array}$ & $1^{\text {st }}$ light \\
\hline $\begin{array}{l}\text { GLAO } \\
\text { Wide Field (\#2) } \\
\text { (Ground Layer) }\end{array}$ & $0.31-1.0 \mu$ & - Large sample galaxy spectra & $\begin{array}{l}\text {-Optical multiobject } \\
\text { spectrograph }\end{array}$ & $\begin{array}{l}\text { Option on } 1^{\text {st }} \\
\text { light wide-field } \\
\text { instrument }\end{array}$ \\
\hline $\begin{array}{l}\text { ExAO } \\
\text { Extreme }(\# 5)\end{array}$ & $1-2.5 \mu$ & $\begin{array}{l}\text {-Exo planet imaging } \\
\text {-Protoplanetary disks }\end{array}$ & $\begin{array}{l}\text {-MEMS } \\
\text {-Coronagraph or Nulling } \\
\text { Interferometer Planet Imager }\end{array}$ & Not yet known \\
\hline $\begin{array}{l}\text { MCAO } \\
\text { Multiconjugate (\#8) }\end{array}$ & $0.8-5 \mu$ & $\begin{array}{l}\text {-Dark ages } \\
\text {-Early galaxies, AGNs } \\
\text { - Nearby galaxies resolved star pop. and nuclei } \\
\text {-Galactic Center } \\
\text {-Star forming regions }\end{array}$ & $\begin{array}{l}\text {-Multi Lasers } \\
\text {-Tomography } \\
\text {-Single or multi- DM } \\
\text {-IFU (with imaging) }\end{array}$ & $\begin{array}{l}2^{\text {nd }} \text { light, } \\
\text { assuming } \\
\text { MOAO } \\
\text { validation }\end{array}$ \\
\hline
\end{tabular}

Table 2. Example distribution of scientific priorities onto 5 AO observing modes: Multiobject AO (MOAO), MidInfrared AO (MIRAO), Ground-Layer AO (GLAO), Extreme contrast AO (ExAO), and Multiconjugate AO (MCAO).

- Accelerates the design process by procedurally eliminating highest-risk options (risk avoidance)

- Identifies top investment priorities among component prototypes, lab experiments, and sky demonstrations

- Allows tracking of risk mitigation strategy effectiveness over time (through periodic reassessment)

- Allows objective monitoring of external/vendor-based technology development progress

- Provides objective criteria to facilitate technical communication among distributed engineering teams

- Encourages thorough canvassing of available technologies

- Provides a structure for updating engineer knowledge of technology state-of-the-art

- Helps documents design-choice rationale

As caveats, quantitative risk assessment:

- Can inform, but should never replace sound engineering judgment

- $\quad$ Requires careful vetting of individual assignments of weight factors.

This last point, in fact, provides another tool for the conceptual development. Where multiple independent assessments of the same technical risk produce widely disparate results, this implies that either one party lacks information or that the two parties have failed to adequately define the risk area. Both are valuable faults to identify early in the project life cycle. 


\begin{tabular}{|c|c|c|c|}
\hline Risk Area & $\begin{array}{l}\text { Needed to meet } \\
\text { Science Requirement }\end{array}$ & Achieved today & $\begin{array}{l}\text { Risk mitigation / } \\
\text { fall-back }\end{array}$ \\
\hline DMs & $\begin{array}{l}-10 \mathrm{k} \text { actuators } \\
\text { - } 11 \mu \text { stroke } \\
\text { - Cryo/cold operation (?) } \\
\text { - Curved (?) }\end{array}$ & $\begin{array}{l}\text { - } 1 \mathrm{k} \text { actuators } \\
\text { - } 5 \mu \mathrm{PZT} ; 2.5 \mu \mathrm{MEMS} \\
\text { - Room temp } \\
\text { - } \$ 200 / \text { actuator } \\
\text { - Flat }\end{array}$ & $\begin{array}{l}\text { - DM development } \\
\text { - Woofer } \\
\text { - Operate DM(s) warm } \\
\text { - Low order AO }\end{array}$ \\
\hline Adaptive Secondary & $\begin{array}{l}\text { - Woofer: } 36 \text { dof } 11 \mu \text { stroke } \\
\text { - MIRAO: } 1000 \text { dof } 11 \mu \text { (+ Tip/Tilt: } \\
125 \mu \text { stroke) } \\
\cdot D=2.3 \mathrm{~m} \text { or } 3.5 \mathrm{~m}\end{array}$ & $\begin{array}{l}\cdot 336 \text { dof (MMT) } \\
\cdot 10-20 \mu \text { stroke } \\
\cdot D=0.6 \mathrm{~m}\end{array}$ & $\begin{array}{l}\text { - High stroke MEMS development } \\
\text { - AM2 development } \\
\text { - Use alternative woofer DM }\end{array}$ \\
\hline Wavefront Sensors & $\begin{array}{l}\text {-250-500k pixels } \\
\text { - Laser elongation tracking (?) }\end{array}$ & - $16 \mathrm{k}$ pixels & $\begin{array}{l}\text { - Chip development } \\
\text { - Lower order AO correction }\end{array}$ \\
\hline IR Tip/Tilt Sensors & $\begin{array}{l}\text { - Low Noise ( 2e-) } \\
\text { - Pyramid sensors (?) }\end{array}$ & $\cdot 20$ e- & $\begin{array}{l}\text { - Sensor development } \\
\text { - Lower sky coverage }\end{array}$ \\
\hline Lasers & $\begin{array}{l}\text { - 50-500 Watts @ } 589 \mathrm{~nm} \text { (total } \\
\text { from multiple lasers) } \\
\text { - Possibly needing } 3 \mu \mathrm{s} \text { pulse for } \\
\text { elongation mitigation or } 150 \mu \mathrm{s} \\
\text { pulse for gating out fratricide }\end{array}$ & $\begin{array}{l}\cdot 10-15 \text { Watts short-pulse (Keck) } \\
\cdot 20 \text { Watts CW (USAF) } \\
\cdot 8 \text { Watts macropulse/micropulse } \\
\text { (U Chicago) }\end{array}$ & $\begin{array}{l}\text { - Laser development } \\
\text { - } \underline{\text { CW laser }}\end{array}$ \\
\hline $\begin{array}{l}\text { Tomography / Computers / } \\
\text { Algorithms }\end{array}$ & $\begin{array}{l}\cdot 60 \mathrm{kx} 60 \mathrm{k} \text { VMM } \\
\cdot \text { - Matrix Inverse as cond's change }\end{array}$ & $\begin{array}{l}\text { - } 1 \mathrm{k} \times 1 \mathrm{k} \text { VMM / custom processor } \\
\text { - Pre-stored matrices }\end{array}$ & $\begin{array}{l}\text { - Fast algorithm development } \\
\text { - Moore's law }\end{array}$ \\
\hline Photometric accuracy & $\begin{array}{l}\cdot 2 \% \text { over } 10 \text { min @ } 1 \mu \text { over } 30 " \\
\text { FOV }\end{array}$ & - 'few' \% (CFHT) on axis & $\begin{array}{l}\text { - PSF reconstruction algorithm } \\
\text { - On-site } C_{n}^{2}(h) \text { profile measurement }\end{array}$ \\
\hline Astrometric accuracy & - $10-100$ ras & - 500-1000 $\mu$ as (Keck) & $\begin{array}{l}\text { - Mech stability, star ref. Grid } \\
\text { - Active metrology }\end{array}$ \\
\hline
\end{tabular}

Table 3. Major adaptive optics subsystem requirements, risks, and potential mitigations, based upon conceptual error budgets still under development. Here, the symbol (?) indicates (some) potential needs not yet confirmed.

\section{QUANTITATIVE RISK ASSESSMENT (QRA) PROCEDURE}

While there are many procedures for quantitative risk assessment in the literature, our desire to strongly emphasize early cost risk mitigation leads us to consider a formalism drawn from techniques commonly used by the aerospace industry ${ }^{12,13,14}$ and similar to guidelines used in the evaluation of cost contingency in other large, complex scientific projects ${ }^{15}$. It is by no means the only choice. Among its limitations, the procedure is insufficient to properly evaluate the impact to scientific return among different technical alternatives, the exposure of the project to long leadtime technology development programs, nor the fungibility of alternative components as fallback technology options. Still, as a measure of technical maturity of a concept, we find this formalism satisfactory.

The mechanism of our quantitative risk assessment (QRA) process is as follows:

1. Enumerate the system components and architecture choices envisioned as potentially meeting each AO system error budget allocation. Enough detail should be included in the specification to distinguish the technology requirement from one resulting a different technical risk score. (Alternatively, if at the end of the process, components of the same type result in the same risk score, these likely can be combined into a more general description that describes both.)

Example components:

"CCD arrays of $256^{2}$ format with 2e- read noise and 16 read-out amplifiers"

"CCD arrays of $256^{2}$ format with $5 \mathrm{e}$ - read noise and 4 read-out amplifiers"

"PMN DM's have 8000 actuators and 350mm diameter"

"MEMS-based DM's have 8000 actuators and 120mm diameter" 
Examples architectures: $\quad$ "Ground-layer wavefront sensing using only natural guide stars"

"Ground-layer wavefront sensing using only Rayleigh beacons"

"Ground-layer wavefront sensing using combinations of natural guide stars and Rayleigh beacons"

2. Assign risk factors and weights to architectures (based on technical readiness) and to components (based on technical, design, schedule, and cost uncertainties), using the tables presented in Tables 4 through 9.:

For components:

$$
\begin{array}{lll}
\mathrm{F}_{\mathrm{T}} & =\text { Technical Risk Factor: } & \text { Reflects technical maturity } \\
\mathrm{W}_{\mathrm{T}} & =\text { Technical Weight: } & \text { Reflects technical complexity } \\
\mathrm{F}_{\mathrm{D}} & =\text { Design Risk Factor: } & \text { Reflects design maturity (e.g. large } \mathrm{F}_{\mathrm{D}} \text { during conceptual design) } \\
\mathrm{F}_{\mathrm{C}} & =\text { Cost Risk Factor: } & \begin{array}{l}
\text { Reflects lack of information on cost basis } \\
\mathrm{W}_{\mathrm{C}}
\end{array} \\
\mathrm{F}_{\mathrm{S}} & =\text { Cost Weight: } & \text { Reflects labor only risk (=1) or labor and material cost risk (=2) }
\end{array}
$$

Note, that early in a project's life cycle, uncertainty component cost estimation is likely to exist in both labor and raw materials costs. Accordingly, until the project reaches routine component production, it is appropriate to consistently set $\mathrm{W}_{\mathrm{C}}=2$.

For architecture choices:

$$
\mathrm{F}_{\mathrm{TRL}}=\text { TRL Risk Factor: }
$$

Reflects the Technology Readiness Level (TRL) system architecture, operational model, or implementation concept available to the AO system designer

The TRL levels considered here will be familiar to readers from the DoD or NASA communities. The TRL risk factor scale has been devised here, using a number of example AO system prototyping scenarios, in order to establish a scale commensurate with that for component technical development risk.

3. Evaluate one or more combinations of base risk factors to determine the overall risk for developing needed technology. The most basis such derived metrics is known as the Technical Development Risk

Technical Development Risk, $\mathrm{R}_{\mathrm{D}}$

(Assesses technical challenge of the risk item without regard to system impact or cost)

$$
\begin{array}{ll}
\mathrm{R}_{\mathrm{D}}=\left(\mathrm{W}_{\mathrm{T}} \mathrm{F}_{\mathrm{T}}+\mathrm{F}_{\mathrm{D}}+\mathrm{W}_{\mathrm{C}} \mathrm{F}_{\mathrm{C}}+\mathrm{F}_{\mathrm{S}}\right) & \text { for components } \\
\mathrm{R}_{\mathrm{D}}=\mathrm{W}_{\mathrm{T}} \mathrm{F}_{\mathrm{TRL}} & \text { for architectures }
\end{array}
$$

Values of $R_{D}$ less than 25 generally represent established technologies, or slight improvements thereupon. Values of 26-50 indicate areas where new initiatives for risk mitigation may be considered, depending on external commercial drivers and the available lead-time. Values of 51-100 indicate areas where considerable technical risk exists and risk mitigation initiatives are highly recommend. For values above 100, the capability of the technique to accurately capture even relative risk areas must be questioned, though the need for at least one full 'next generation' of development seems undisputable. (It has been suggested that values of $R_{D} \sim 200$ correspond to areas requiring 'two generations' of technical advancement, but only few supporting examples of this have been identified.) 


\begin{tabular}{|c|c|c|c|}
\hline $\mathbf{F}_{\mathbf{T}}$ & $\begin{array}{c}\text { Risk } \\
\text { Range }\end{array}$ & Definition & Example(s) \\
\hline 1 & Low & $\begin{array}{l}\text { Existing design can be purchased off } \\
\text { the shelf }\end{array}$ & $\begin{array}{l}\text { Commercial wavefront sensor camera running } \\
\text { an } 80 \times 80 \text { pixel CCD with } 4 \text { readout amplifiers }\end{array}$ \\
\hline 2 & Low & $\begin{array}{l}\text { Minor modifications required to an } \\
\text { existing design }\end{array}$ & $\begin{array}{l}\text { Commercial camera running new timing } \\
\text { sequence }\end{array}$ \\
\hline 3 & Low & $\begin{array}{l}\text { Major Modifications required to an } \\
\text { existing design }\end{array}$ & $\begin{array}{l}\text { Commercial camera running a } 128 \times 128 \text { pixel } \\
\text { CCD, still } 4 \text { readout amplifiers }\end{array}$ \\
\hline 4 & Medium & New design required: Routine & $\begin{array}{l}\text { New camera design using new board layout } \\
\text { and new commercial opamps }\end{array}$ \\
\hline 5 & Medium & New design required: Non-routine & $\begin{array}{l}\text { New camera design with new board layout and } \\
\text { significantly more readout amplifiers }\end{array}$ \\
\hline 6 & Medium & $\begin{array}{l}\text { New design required: Some } R \& D \\
\text { required to solve novel problems }\end{array}$ & $\begin{array}{l}\text { New camera running at unprecedented speed } \\
\text { requires use of new data transfer bus }\end{array}$ \\
\hline 7 & Medium & $\begin{array}{l}\text { New design required: More than half } \\
\text { of the design requires } R \& D \text { to solve } \\
\text { novel problems }\end{array}$ & $\begin{array}{l}\text { New camera using an application specific } \\
\text { integrated circuit (ASIC) that has been } \\
\text { successfully used in other designs. }\end{array}$ \\
\hline 8 & High & $\begin{array}{l}\text { New design required: More than } 90 \% \\
\text { of the design requires R\&D to solve } \\
\text { novel problems }\end{array}$ & $\begin{array}{l}\text { New camera using an ASIC that has been } \\
\text { prototyped, along with a new board layout }\end{array}$ \\
\hline 9 & High & $\begin{array}{l}\text { State of the art design required: All } \\
\text { problems are novel or untried }\end{array}$ & $\begin{array}{l}\text { New camera using a new, untried ASIC with } \\
\text { higher internal clock speed than attempted } \\
\text { before }\end{array}$ \\
\hline 10 & High & $\begin{array}{l}\text { State of the art design required: } \\
\text { Design is untried, unknown and exotic } \\
\text { compared with any existing design }\end{array}$ & $\begin{array}{l}\text { New camera using new, untried CCD design } \\
\text { along with new, untried ASIC operating at } \\
\text { unprecedented frame rates }\end{array}$ \\
\hline
\end{tabular}

Table 4. Technical Risk Factors, $F_{T}$

\begin{tabular}{|c|c|l|l|}
\hline $\mathbf{W}_{\mathbf{T}}$ & $\begin{array}{c}\text { Risk } \\
\text { Range }\end{array}$ & \multicolumn{1}{|c|}{ Definition } & \multicolumn{1}{c|}{ Example(s) } \\
\hline 1 & Low & $\begin{array}{l}\text { System is not complex; low part } \\
\text { counts; well-defined engineering } \\
\text { techniques can be used for design and } \\
\text { manufacturing }\end{array}$ & $\begin{array}{l}\text { 349 actuator deformable mirrors; } \\
\text { Least-squares vector-matrix multiple } \\
\text { wavefront control algorithm }\end{array}$ \\
\hline 2 & Medium & $\begin{array}{l}\text { System is moderately complex; } \\
\text { moderate part counts; or technology } \\
\text { needed is 'next generation' }\end{array}$ & $\begin{array}{l}3000 \text { actuator deformable mirrors; Efficient } \\
\text { wavefront control algorithms }\end{array}$ \\
\hline 8 & Medium & $\begin{array}{l}\text { System is moderately complex; large } \\
\text { part counts; or technology needed } \\
\text { requires two distinct generations of } \\
\text { development }\end{array}$ & $\begin{array}{l}\text { 9000 actuator deformable mirrors; } \\
\text { Hierarchical wavefront control utilizing } \\
\text { woofer/tweeter architectures }\end{array}$ \\
\hline 8 & High & $\begin{array}{l}\text { System is highly complex; large part } \\
\text { counts; technology needed requires } \\
\text { more than two distinct generations of } \\
\text { development }\end{array}$ & $\begin{array}{l}\text { 100,000 actuator deformable mirrors; Global } \\
\text { wavefront control optimization including } \\
\text { telescope, AO system, and instrumentation }\end{array}$ \\
\hline
\end{tabular}

Table 5. Technical Weight Factors, $W_{T}$ 


\begin{tabular}{|c|l|l|l|}
\hline $\mathbf{F}_{\mathbf{D}}$ & $\begin{array}{c}\text { Risk } \\
\text { Range }\end{array}$ & \multicolumn{1}{|c|}{ Definition } & \multicolumn{1}{c|}{ Example(s) } \\
\hline 1 & Low & $\begin{array}{l}\text { Detailed design is greater than } \\
50 \% \text { done. }\end{array}$ & $\begin{array}{l}\text { Initial design is complete and documented, test } \\
\text { plan completed, detailed design more than 50\% } \\
\text { done }\end{array}$ \\
\hline 2 & Low & $\begin{array}{l}\text { Detailed design is about 25\% } \\
\text { done. }\end{array}$ & Same as above except detailed design is 25\% done. \\
\hline 3 & Low & $\begin{array}{l}\text { Preliminary design and analysis } \\
\text { are 100\% done }\end{array}$ & $\begin{array}{l}\text { Initial design is complete and documented, test } \\
\text { plan completed, but detailed design has not begun } \\
\text { Vendors have responded to RFQs with preliminary } \\
\text { designs }\end{array}$ \\
\hline 5 & Medium & $\begin{array}{l}\text { Preliminary design and analysis } \\
\text { are 75\% done }\end{array}$ & $\begin{array}{l}\text { Initial design well underway, results from } \\
\text { simulations and analysis 75\% complete }\end{array}$ \\
\hline 6 & Medium & $\begin{array}{l}\text { Preliminary design and analysis } \\
\text { are 50\% done }\end{array}$ & $\begin{array}{l}\text { Initial design well underway, results from } \\
\text { simulations and analysis 50\% complete }\end{array}$ \\
\hline 7 & Medium & $\begin{array}{l}\text { Preliminary design and analysis } \\
\text { are 10\% }\end{array}$ & $\begin{array}{l}\text { Preliminary design is partly done and simulations } \\
\text { and analysis have been started. }\end{array}$ \\
\hline 10 & High & $\begin{array}{l}\text { Conceptual design, final } \\
\text { requirements, specifications, } \\
\text { are complete. }\end{array}$ & $\begin{array}{l}\text { Initial drawings not started. } \\
\text { Simulations are not started. } \\
\text { Request for Quotations (RFQ's) ready to be } \\
\text { released. }\end{array}$ \\
\hline 9 & High & $\begin{array}{l}\text { Concept, requirements \& rough } \\
\text { specifications, sketches/ block } \\
\text { diagram only are complete }\end{array}$ & $\begin{array}{l}\text { "We're pretty sure we can generate a 3 } \mu \text { sec laser } \\
\text { pulse by chopping a CW beam with a wheel, } \\
\text { spinning at 500 rpm, having a gap size..." }\end{array}$ \\
\hline not started.
\end{tabular}

Table 6. Design Risk Factors, $F_{D}$.

\section{QRA EXAMPLE}

As an example of one implementation of the RQA formalism, we present a snapshot in time of a portion of our working risk assessment spreadsheet in Table 10. As various groups within TMT and external to it progress in successfully demonstrating laboratory and on-sky validation of these techniques, this assessment will be updated.

\section{REQUIREMENTS GUIDELINES}

As we progress through the process outlined in Figure 1, we have as our goal the development of requirements that capture the essence of the project goals with minimal complexity and maximal design freedom. Toward this end, the actual wording of the Functional Requirements Documents (FRDs) matters. We therefore present one definition and a set of desirable properties of written requirements ${ }^{16}$.

A requirement is a necessary, quantifiable, and verifiable capability, function, property, characteristic, or behavior that a product must exhibit to solve a real-world problem, or a constraint that a product or a product's development process must satisfy ${ }^{17}$. Requirements must be: 


\begin{tabular}{|c|c|l|l|}
\hline F $_{\mathbf{C}}$ & $\begin{array}{c}\text { Risk } \\
\text { Range }\end{array}$ & \multicolumn{1}{|c|}{ Definition } & \multicolumn{1}{|c|}{ Example(s) } \\
\hline 1 & Low & Off the shelf catalog item. & $\begin{array}{l}\text { A standard off-axis parabola (OAP) available from } \\
\text { several vendors }\end{array}$ \\
\hline 2 & Low & $\begin{array}{l}\text { Vendor quote from established } \\
\text { drawings }\end{array}$ & $\begin{array}{l}\text { Drawings are detailed, e.g. an OAP that has been } \\
\text { prototyped }\end{array}$ \\
\hline 3 & Low & $\begin{array}{l}\text { Vendor quote from design } \\
\text { sketches }\end{array}$ & $\begin{array}{l}\text { Quote based on specification and tolerances supplied } \\
\text { to vendor without production drawings }\end{array}$ \\
\hline 4 & Medium & $\begin{array}{l}\text { In-house estimate from previous } \\
\text { experience }\end{array}$ & $\begin{array}{l}\text { OAP cost estimate, based on amount of removed } \\
\text { material, known from previous engineer experience }\end{array}$ \\
\hline 5 & Medium & $\begin{array}{l}\text { In-house estimate backed by } \\
\text { limited experience }\end{array}$ & $\begin{array}{l}\text { A large OAP is being estimated based on extensive } \\
\text { experience polishing spherical mirrors and prior } \\
\text { experience polishing small OAPs }\end{array}$ \\
\hline 7 & Medium & $\begin{array}{l}\text { In-house estimate backed by } \\
\text { minimum experience }\end{array}$ & $\begin{array}{l}\text { New OAP design without in-house cost experience. } \\
\text { Vendors may or may not be consulted }\end{array}$ \\
\hline 8 & High & $\begin{array}{l}\text { Top down extimate from a similar } \\
\text { program }\end{array}$ & $\begin{array}{l}\text { A large OAP is being estimated by comparison with } \\
\text { other large OAPs from previous program, without any } \\
\text { detailed design parameters that would allow vendor } \\
\text { input }\end{array}$ \\
\hline 9 & High & $\begin{array}{l}\text { Tow OAP down } \\
\text { colirely on limited cost estimating experience of } \\
\text { roughly similar program }\end{array}$ & $\begin{array}{l}\text { A large OAP is being estimated by comparison with } \\
\text { large mirrors from other projects, without detailed } \\
\text { knowledge of those specifications }\end{array}$ \\
\hline 10 & High & $\begin{array}{l}\text { Engineering judgment with no } \\
\text { available comparables }\end{array}$ & $\begin{array}{l}\text { Senior mechanical engineer without optical fabrication } \\
\text { experience offers ballpark cost estimate }\end{array}$ \\
\hline
\end{tabular}

Table 7. Cost Risk Factors, $\mathrm{F}_{\mathrm{C}}$.

- Quantitative: Strenuous effort should be made to provide quantitative requirements. If numbers are currently unavailable, the placeholder "TBD" , together with appropriate SI units, should be used.

Poor: $\quad$ MCAO supports near-IR operation

Good: MCAO transmission between $0.6-2.5$ um shall be greater than $90 \%$

- Unambiguous: Every requirement must have only one interpretation. Areas of 'desired' functionality and performance shall be clearly labeled using the term 'goal' (use of the word 'should' can also be used to indicate a desire, as contrasted with the more precise 'shall' reserved for requirements).

- Complete: All relevant requirements must be included.

- Verifiable: A requirement is verifiable if and only if there exists some finite, cost-effective process whereby the final product can be checked/tested to meet the requirement. If no method of verification can be devised, either (1) the requirement should be eliminated, or (2) a subsequent point in the development should be identified at which time the requirement can be put into verifiable form (i.e. pending additional information).

- Consistent: No two requirements should conflict with each other.

- Non-redundant: Any requirement entirely superceded by another requirement should be eliminated. 


\begin{tabular}{|c|c|c|c|}
\hline $\mathbf{F}_{\mathrm{S}}$ & $\begin{array}{c}\text { Risk } \\
\text { Range }\end{array}$ & Definition & Example(s) \\
\hline 1 & Low & $\begin{array}{l}\text { Schedule slippage has little or no } \\
\text { impact on another item }\end{array}$ & $\begin{array}{l}\text { A late remote monitoring system that is not essential } \\
\text { to AO system operation }\end{array}$ \\
\hline 2 & Low & $\begin{array}{l}\text { Schedule slippage delays } \\
\text { completion of a non-critical-path } \\
\text { item }\end{array}$ & $\begin{array}{l}\text { A late electronic component which holds up final } \\
\text { testing of some boards in a subsystem }\end{array}$ \\
\hline 3 & Low & $\begin{array}{l}\text { Schedule slippage delays } \\
\text { completion of several non- } \\
\text { critical-path items }\end{array}$ & $\begin{array}{l}\text { A late electronic component which holds up testing of } \\
\text { several subsystems }\end{array}$ \\
\hline 4 & Medium & $\begin{array}{l}\text { Schedule slippage of this item } \\
\text { delays completion of a major } \\
\text { component in a subsystem }\end{array}$ & $\begin{array}{l}\text { A late custom null lens which delays alignment of an } \\
\text { aspheric optic in the Optical Bench System (OBS) }\end{array}$ \\
\hline 5 & Medium & $\begin{array}{l}\text { Schedule slippage of this item } \\
\text { delays completion of several } \\
\text { major components in a subsystem }\end{array}$ & $\begin{array}{l}\text { A late reference flat that delays alignment of all } \\
\text { mirrors in the OBS }\end{array}$ \\
\hline 6 & Medium & $\begin{array}{l}\text { Schedule slippage of this item } \\
\text { delays completion of a minor } \\
\text { subsystem }\end{array}$ & $\begin{array}{l}\text { A large stroke uplink tip/tilt mirror which can be } \\
\text { swapped with an available smaller stroke mirror for } \\
\text { initial installation }\end{array}$ \\
\hline 7 & Medium & $\begin{array}{l}\text { Schedule slippage delays } \\
\text { completion of multiple minor } \\
\text { subsystems }\end{array}$ & $\begin{array}{l}\text { A generic piece of software that supports the interface } \\
\text { with several weather stations }\end{array}$ \\
\hline 8 & High & $\begin{array}{l}\text { Schedule slippage delays } \\
\text { completion of a major subsystem }\end{array}$ & $\begin{array}{l}\text { A late deformable mirror which delays completion of } \\
\text { the wavefront control subsystem; alignment of the } \\
\text { OBS can proceed using a non-adaptive replacement } \\
\text { mirror }\end{array}$ \\
\hline 9 & High & $\begin{array}{l}\text { Schedule slippage delays } \\
\text { completion of multiple major } \\
\text { systems }\end{array}$ & $\begin{array}{l}\text { A late optical bench which precludes hardware I\&T; } \\
\text { software development can proceed }\end{array}$ \\
\hline 10 & High & $\begin{array}{l}\text { Schedule slippage delays } \\
\text { completion of the entire } \\
\text { instrument. }\end{array}$ & $\begin{array}{l}\text { Delay in telescope secondary delays all testing of an } \\
\text { adaptive secondary MIRAO system }\end{array}$ \\
\hline
\end{tabular}

Table 8. Schedule Risk Factors, $F_{S}$.

- Modifiable: The structure and style of this section should allow necessary changes be made easily, completely, and consistently.

- Traceable: Requirements should be both backward traceable (referencing the source of the requirement, such as a result of specific Science Requirement or Observatory Standard) and forward traceable (with unique numbering so as to be identified/referenced in subsequent detailed design requirements or test documentation).

- Usable during design (and relevant to operations and maintenance): Often items are modified during the product lifecycle. The requirements should call out critical areas (such as failures that can result in human hazard), and other information that should not be lost to maintenance personnel. 


\begin{tabular}{|c|c|c|l|l|}
\hline $\mathbf{F}_{\text {TRL }}$ & $\begin{array}{c}\text { TRL } \\
\text { Level }\end{array}$ & $\begin{array}{c}\text { Risk } \\
\text { Range }\end{array}$ & \multicolumn{1}{|c|}{ Definition } & \multicolumn{1}{|c|}{ Example(s) } \\
\hline 2 & 9 & Low & $\begin{array}{l}\text { Actual system proven in the field } \\
\text { through successful operation }\end{array}$ & $\begin{array}{l}\text { Reproduction of an AO system working } \\
\text { at the TMT }\end{array}$ \\
\hline 4 & 8 & Low & $\begin{array}{l}\text { Actual system proven through test } \\
\text { and demonstration }\end{array}$ & $\begin{array}{l}\text { TMT AO system passing pre-ship } \\
\text { review }\end{array}$ \\
\hline 6 & 7 & Low & $\begin{array}{l}\text { System prototype demonstrated in } \\
\text { working environment }\end{array}$ & $\begin{array}{l}\text { Performance of Gemini South MCAO } \\
\text { system confirmed }\end{array}$ \\
\hline 10 & 6 & Medium & $\begin{array}{l}\text { System/subsystem validation } \\
\text { model or prototype demonstrated } \\
\text { in working environment }\end{array}$ & $\begin{array}{l}\text { Adaptive laser uplink correction } \\
\text { demonstrated to meet performance at } \\
\text { existing telescope }\end{array}$ \\
\hline 12 & 4 & Medium & $\begin{array}{l}\text { Component or breadboard } \\
\text { validation in working } \\
\text { environment }\end{array}$ & $\begin{array}{l}\text { New sodium laser field tested at existing } \\
\text { telescope at final required power levels }\end{array}$ \\
\hline 20 & 3 & Medium & $\begin{array}{l}\text { Component or breadboard } \\
\text { validation in laboratory } \\
\text { environment }\end{array}$ & $\begin{array}{l}\text { New sodium laser tested in the lab at } \\
\text { final required power levels; } \\
\text { Three-conjugate correction } \\
\text { demonstrated to meet performance } \\
\text { prediction in the lab }\end{array}$ \\
\hline 40 & 2 & High & $\begin{array}{l}\text { Analytical and experimental } \\
\text { critical function and/or } \\
\text { characteristic proof of concept }\end{array}$ & $\begin{array}{l}\text { Scalable power laser demonstrated in the } \\
\text { lab at below final required power level; } \\
\text { Three-conjugate control algorithm } \\
\text { demonstrated at quasi-static update rates }\end{array}$ \\
\hline observed and reported & $\begin{array}{l}\text { Peer-reviewed concept for new } \\
\text { wavefront sensing architecture } \\
\text { published; } \\
\text { AO system simulation incorporating } \\
\text { majority of relative physics; } \\
\text { Unproven design for new sodium laser } \\
\text { proposed by vendor }\end{array}$ \\
\hline application formulated & $\begin{array}{l}\text { Abstract AO system simulation of single } \\
\text { subsystem; } \\
\text { Laser sum-frequency mixing in a non- } \\
\text { linear crystal reported }\end{array}$ \\
\hline & 1 & High & & \\
\hline
\end{tabular}

Table 9. Technology Readiness Level (TRL) Risk Factors, $\mathrm{F}_{\mathrm{TRL}}$.

\section{ACKNOWLEDGEMENTS}

The Thirty Meter Telescope (TMT) Project is a partnership of the Association of Universities for Research in Astronomy (AURA), the Association of Canadian Universities for Research in Astronomy (ACURA), the California Institute of Technology and the University of California. The partners gratefully acknowledge the support of the Gordon and Betty Moore Foundation, the US National Science Foundation, the National Research Council of Canada, the Natural Sciences and Engineering Research Council of Canada, and the Gemini Partnership. 


\begin{tabular}{|c|c|c|c|c|c|c|c|c|c|c|c|c|c|c|c|c|}
\hline \multirow[b]{2}{*}{$\begin{array}{c}\text { Functional } \\
\text { area }\end{array}$} & \multirow[b]{2}{*}{$\begin{array}{c}\begin{array}{c}\text { Architecture } \\
\text { Risk }\end{array} \\
\end{array}$} & \multicolumn{5}{|c|}{ Architecture risk assessment } & \multicolumn{10}{|c|}{ Component risk assessment } \\
\hline & & $F_{\text {TRL }}$ & $\mathbf{W}_{\mathbf{T}}$ & $\mathbf{R}_{\mathrm{D}}$ & $\begin{array}{c}\begin{array}{c}\text { Architecture } \\
\text { notes }\end{array} \\
\end{array}$ & Risk mitigation & Component risk & $\mathbf{F}_{\mathrm{T}}$ & $\mathrm{W}_{\mathrm{T}}$ & $F_{D}$ & $F_{\mathrm{C}}$ & $\mathbf{w}_{\mathrm{c}}$ & $F_{\mathrm{S}}$ & $\mathbf{R}_{\mathrm{D}}$ & Comments & Risk miigation \\
\hline $\begin{array}{l}\text { Wavefront } \\
\text { Sensing }\end{array}$ & $\begin{array}{c}\text { Rayleigh lasers } \\
\text { WFS }\end{array}$ & 4 & 1 & 4 & \begin{tabular}{|l|} 
Architecture also \\
requires (1) real-time \\
background \\
subtraction and (2) \\
WFS geometries \\
matched to elongated \\
spots
\end{tabular} & $\begin{array}{l}\text { (1) Lab and field tests of } \\
\text { wavefront sensing with } \\
\text { elongated spots and (2) } \\
\text { lab tests of real-time } \\
\text { background subtraction }\end{array}$ & $\begin{array}{l}\text { 30-Watt class } \\
\mathrm{CW} / \mathrm{QCW} \text { laser }\end{array}$ & 3 & 2 & 7 & 5 & 2 & 8 & 31 & $\begin{array}{l}\text { Estimated power } \\
\text { requirement based } \\
\text { upon simulations of } \\
\text { "Floor" MCAO } \\
\text { system }\end{array}$ & $\begin{array}{l}\text { (1) Futher modeling to } \\
\text { estimate power } \\
\text { requirement, then (2) } \\
\text { purchase laser }\end{array}$ \\
\hline $\begin{array}{l}\text { Wavefront } \\
\text { Sensing }\end{array}$ & $\begin{array}{l}\text { CW Na laser } \\
\text { WFS }\end{array}$ & 4 & 1 & 4 & $\begin{array}{l}\text { Architecture requires } \\
\text { Rayleigh supression } \\
\text { and possibly line } \\
\text { spreading to avoid } \\
\text { saturation }\end{array}$ & (1) and (2) as above & $\begin{array}{c}50-\text { Watt class CW Na } \\
\text { laser }\end{array}$ & 3 & 2 & 1 & 5 & 2 & 8 & 25 & & \\
\hline $\begin{array}{l}\text { Wavefront } \\
\text { Sensing }\end{array}$ & $\begin{array}{l}\text { Micropulse / } \\
\text { macropulse Na } \\
\text { laser WFS }\end{array}$ & 8 & 2 & 16 & $\begin{array}{l}\text { Requires WFS geom } \\
\text { matched to elongated } \\
\text { spots }\end{array}$ & (1) and (2) as above & $\begin{array}{c}\text { 20-Watt class MMP } \\
\text { Na laser }\end{array}$ & 4 & 2 & 7 & 5 & 2 & 8 & 33 & $\begin{array}{l}\text { Estimated power } \\
\text { requirement based } \\
\text { upon simulations of } \\
\text { "Floor" MCAO } \\
\text { system }\end{array}$ & (1) and (2) above \\
\hline $\begin{array}{l}\text { Wavefront } \\
\text { Sensing }\end{array}$ & $\begin{array}{l}\text { Short-pulse } \\
\text { ( 3us) laser- } \\
\text { tracking WFS }\end{array}$ & 8 & 4 & 32 & $\begin{array}{l}\text { Requires WFS } \\
\text { dynamic refocusing }\end{array}$ & $\begin{array}{l}\text { (3) Field tests of LGS } \\
\text { wavefront sensing with } \\
\text { dynamic refocusing }\end{array}$ & $\begin{array}{l}\text { 18-Watt class SP Na } \\
\text { laser }\end{array}$ & 7 & 4 & 8 & 8 & 2 & 8 & 60 & $\begin{array}{l}\text { Estimated power } \\
\text { requirement based } \\
\text { upon simulations of } \\
\text { "Floor" MCAO } \\
\text { system ( } 40 \% \\
\text { reduction with } \\
\text { dynamic refocusing) }\end{array}$ & (1) and (2) above \\
\hline
\end{tabular}

Table 10. Example portion of a quantitative risk assessment spreadsheet describing (a few) options for laser wavefront sensing technical and pulse format. Risk factors are assigned using the guidelines within Tables 4 through 9.

\section{REFERENCES}

${ }^{1}$ Dekany, R., et al., "Initial concepts for CELT adaptive optics," Proc. SPIE Vol. 4839, p. 1165-1174.

2 Troung, T., et al., "Real-time wavefront processors for the next generation of adaptive optics systems: a design and analysis, Proc. SPIE Vol. 4839, p. 911-922.

${ }^{3}$ Ellerbroek, B. L., "Wavefront Reconstruction Algorithms and Simulation Results for Multi-Conjugate Adaptive Optics on Giant Telescopes", Proc. of the $2^{\text {nd }}$ Backaskog Workshop on Extremely Large Telescopes (2004).

${ }^{4}$ Dekany, R., "Exo-Earth Study with TMT", Proc. of the $2^{\text {nd }}$ Backaskog Workshop on Extremely Large Telescopes (2004).

${ }^{5}$ Ellerbroek, B. L. and Buchroeder, R. A., "Near-infrared AO coronagraph design for giant telescopes", Proc. SPIE Vol. 4840, p. 404-414.

${ }^{6}$ Hooks, I. F. and Farry, K. A., Customer centered products: Creating successful products through smart requirements management, Amacom (2001), ISBN 0-8144-0568-1.

${ }^{7}$ Wheatcraft, L., INCOSE INSIGHT, January 2002, Vol 4 Issue 4.

${ }^{8}$ Britton, M., "The Arroyo Project", Proc. SPIE Vol. 5497.

${ }^{9}$ Nelson, J., et al., "Science-based Requirements Document (SRD)," TMT Report 52.

${ }^{10}$ Jollisaint, L., et al., "Wide field adaptive optics upper limit performances," Proc. of the $2^{\text {nd }}$ Backaskog Workshop on Extremely Large Telescopes (2004).

${ }^{11}$ Ellerbroek, B. L., et al., "MCAO for Gemini South", Proc. SPIE Vol. 4839, p. 55-66.

${ }^{12}$ Lee, H. and Olds, J. R., "Integration of cost modeling and business simulation into conceptual launch vehicle design," AIAA 97-3911.

${ }^{13}$ Pritchard, C., Risk Management: Concepts and Guidance, ESI International, (2001).

${ }^{14}$ Oswaldt, P. F., Engineering Cost Estimating, $3^{\text {rd }}$ ed., Prentice-Hall.

${ }^{15}$ Sanders, G., Project Science Workshop, California Institute of Technology, Nov 18-19, 2002.

${ }^{16}$ Kandt, R., K., "Software Requirements Engineering: Practices and Techniques," Software Quality Improvement Report R-3, JPL Document D-24994 (2003).

${ }^{17}$ Kandt, R., K., "Software Configuration Management Best Principles," PROFES 2002, LNCS 2559, Springer-Verlag, p. 300-313 (2002). 